\title{
BMJ Open Predictive validity of PRISMA-7 as a screening instrument for frailty in a hospital setting
}

\author{
Sarah Hoffmann, ${ }^{1}$ Amalie Wiben, ${ }^{2}$ Marie Kruse (D) , ${ }^{2}$ Katja Kemp Jacobsen, ${ }^{3}$ \\ Maurice A Lembeck, ${ }^{1}$ Ellen Astrid Holm (i) ${ }^{1,4}$
}

To cite: Hoffmann S, Wiben A, Kruse M, et al. Predictive validity of PRISMA-7 as a screening instrument for frailty in a hospital setting. BMJ Open 2020;10:e038768. doi:10.1136/ bmjopen-2020-038768

- Prepublication history and additional material for this paper is available online. To view these files, please visit the journal online (http://dx.doi.org/10. 1136/bmjopen-2020-038768).

Received 24 March 2020 Revised 23 July 2020 Accepted 08 October 2020
Check for updates

(c) Author(s) (or their employer(s)) 2020. Re-use permitted under CC BY-NC. No commercial re-use. See rights and permissions. Published by BMJ.

${ }^{1}$ Medical Department, Nykøbing F Sygehus, Nykøbing, Sjaelland, Denmark

${ }^{2}$ Danish Centre for Health Economics, University of Southern Denmark, Odense, Syddanmark, Denmark ${ }^{3}$ Department of Technology, Faculty of Health and Technology, University College Copenhagen, Kobenhavn, Hovedstaden, Denmark

${ }^{4}$ Institute of Clinical Medicine, University of Copenhagen, Kobenhavn, Denmark

Correspondence to Dr Ellen Astrid Holm; ellh@regionsjaelland.dk

\section{ABSTRACT}

Objectives Frailty is a major clinical geriatric syndrome associated with serious adverse events including functional disability, falls, hospitalisation, increased morbidity and mortality. The aim of this study was to study the associations between frailty defined as Program of Research to Integrate Services for the Maintenance of Autonomy (PRISMA-7) score $\geq 3$ and use of healthcare resources in hospital and in the municipality as well as association between frailty and mortality.

Design Register-based retrospective study.

Setting The target population consists of patients aged 75 years or above who, during hospital stay, were assessed by a physiotherapist, and at discharge from hospital were prescribed further physical training in the community. Participants 973 individuals aged $75+$ years were included.

Outcome measures We examined associations between frailty and use of healthcare resources in hospital and in the municipality as well as the association between frailty and mortality.

Results 973 individuals aged $75+$ years were included. Of these, $63.9 \%$ had a PRISMA-7 score $\geq 3$ and were thus defined as frail. Frail individuals were older compared with non-frail with mean ages of 84.6 and 80.4 years, respectively, $p>0.001$. Age and gender-adjusted mortality after 1 year was higher among the frail (OR $2.46,95 \% \mathrm{Cl} 1.53$ to 3.97 ). Use of healthcare services in the municipality as well as hospital admissions was significantly higher among frail individuals.

Conclusions Based on these findings we consider PRISMA-7 to be useful in an in-hospital setting as a screening tool to identify frail elderly patients who may profit from further geriatric assessment during hospital stay.

Trial registration number ID REG-070-2017.

\section{BACKGROUND}

There is no single operational definition of frailty. However, experts agree that it refers to an age-related phenomenon of weakening of homeostasis and lack of resilience to endogenous and exogenous stressors. ${ }^{1}$ The gradual decline of physiological reserves due to ageing results in vulnerability towards various stressors. Consequently, illness or other stressor events may have disproportionally

\section{Strengths and limitations of this study}

- The study contributes to the very limited knowledge regarding use of Program of Research to Integrate Services for the Maintenance of Autonomy (PRISMA-7) as a screening tool for frailty in an inhospital setting.

- Associations between use of healthcare services and frailty were assessed based on data from a period of 30, 80 and 190 days before hospital stay.

- Study participants were selected among hospitalised elderly individuals in need of further physical training and may therefore not be valid in other patient groups.

- We did not compare PRISMA-7 to a golden standard of frailty assessment, and we are therefore not able to make any conclusions neither concerning all validation measures nor on specificity and sensitivity measures.

larger impact on elderly individuals, resulting in negative outcomes and triggering cascades of decline, for example, slower and/or poorer recovery leading to disabilities, dependency, excess morbidity and mortality. ${ }^{23}$

Comprehensive geriatric assessment (CGA) may be used to diagnose and to plan intervention in frailty. ${ }^{45}$ However, CGA is a resource-intensive process led by a specialist in geriatric medicine. Several simple screening tools for frailty are available. ${ }^{6}$ One of these is PRISMA-7, being an abbreviation for 'Program of Research to Integrate Services for the Maintenance of Autonomy'. Researchers developed PRISMA-7 as part of a large Canadian study and used it as a casefinding instrument to identify frail elderly people in the community. ${ }^{78}$ PRISMA-7 is a questionnaire with seven dichotomous questions each scoring 0 or 1 point. A score of $\geq 3$ is considered indicative of frailty, see online supplemental appendix for details of the questionnaire.

Clegg et al compared nine simple frailty screening tools applied in community-dwelling 
adults and found that PRISMA-7 had a high sensitivity but only a moderate specificity. ${ }^{6}$ Based on these findings, the British Geriatrics Society recommends that all encounters between health and social care staff and older people in community and outpatient settings should include an assessment for frailty. They recommend PRISMA-7 as one of the possible tools. ${ }^{9} 10$

Only few studies have used PRISMA-7 in an in-hospital setting. O'Caoimh et al compared several screening instruments in the emergency department and found PRISMA-7 to be the most accurate instrument for separating frail from non-frail with an area under the curve of $0.88 .{ }^{11}$ Beauchet $e t$ al evaluated PRISMA-7 as a predictor for length of stay among patients admitted to a geriatric acute ward, and found no significant association between length of stay and PRISMA score. ${ }^{12}$ Elliott et al performed a feasibility study in the emergency department with use of clinical vignettes and concluded that PRISMA-7 as well as other tested instruments was quick, simple and easy to use. ${ }^{13}$
PRISMA-7 has been translated into several languages and validated in several countries, but not, to our knowledge, in any Scandinavian setting. ${ }^{14-19}$

We decided to study the use of PRISMA-7 in a hospital setting since it is simple and quick to perform and already has been validated and recommended for use in a primary setting. ${ }^{10}$

\section{Objectives}

The aim of this study was to evaluate the use of a Danish version of PRISMA-7 and assess the associations of frailty-as measured with PRISMA-7—with use of healthcare resources; including length of hospital stay, use of healthcare resources in the municipalities, readmissions and mortality.

\section{Design and participants}

The study is a retrospective register-based study using data from a clinical quality study combined with data from national health registers. In Denmark, it is mandatory to

Table 1 Baseline characteristics of frail versus non-frail individuals, defined by PRISMA-7 score ( $\geq 3$ vs $<3$ )

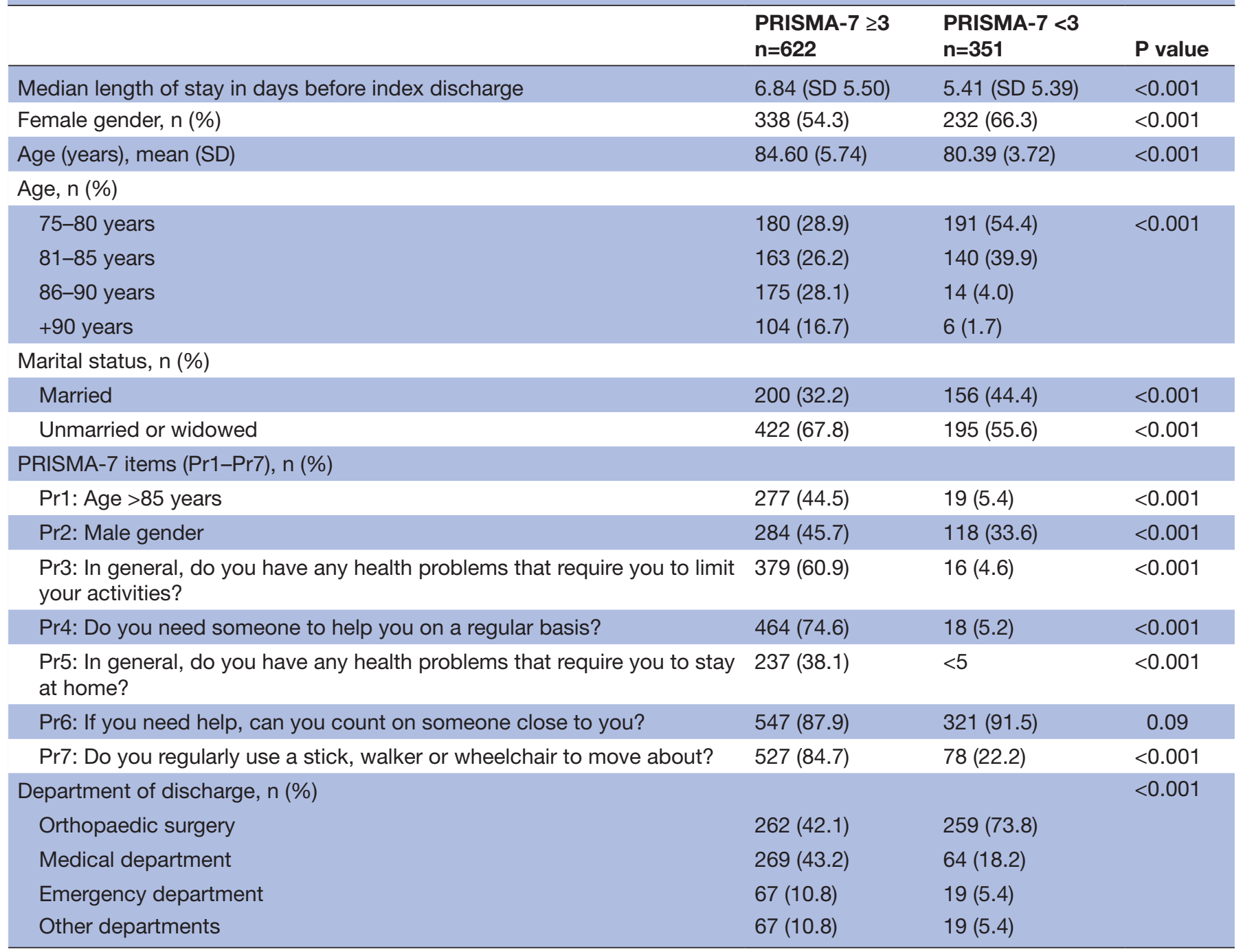

PRISMA, Program of Research to Integrate Services for the Maintenance of Autonomy. 
Table 2 Use of hospital and general practice services among frail compared with non-frail individuals

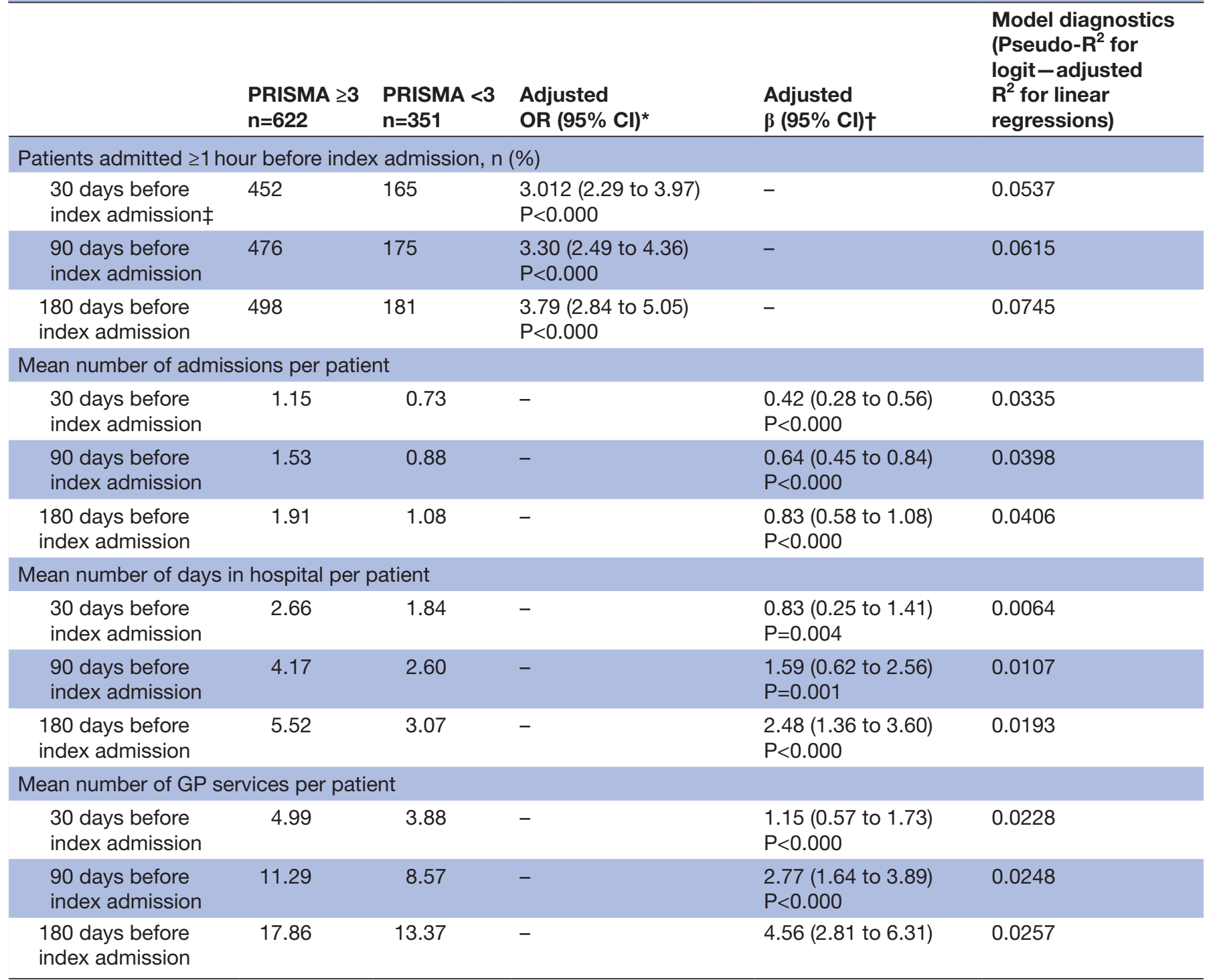

*Logistic regression of binary outcomes adjusted for municipality, OR for frail (PRISMA $\geq 3$ ) compared with non-frail (PRISMA $<3$ ), $p$ value for OR.

†Linear regression of count outcomes adjusted for municipality, $\beta$ coefficient for frail (PRISMA $\geq 3$ ) compared with non-frail (PRISMA $<3$ ), $p$ value for $\beta$ estimate.

$\ddagger$ The index admission is the admission during which PRISMA score was assessed.

GP, general practitioner; PRISMA, Program of Research to Integrate Services for the Maintenance of Autonomy.

assess whether a patient who is dismissed from hospital needs further physical training in the municipality. If the responsible physician finds a need for further training it is the physician's duty to prescribe assessment by a physiotherapist. The physiotherapist will then make a written plan for further training and this plan is shared with the patient and mailed to the municipality. Participants were in-hospital patients aged 75 years or above, for whom the responsible physician had prescribed assessment by a physiotherapist. In this project, the physiotherapist additional to the standard assessment performed screening with PRISMA-7. Participants were included during the period from 1 May 2017 until 31 December 2018. Baseline for each patient is the date of discharge from the index admission defined as the admission during which PRISMA-7 score was assessed.

\section{METHODS}

The clinical quality study included registration of PRISMA-7 scores. These data were stored in a clinical database, henceforth the study database. The study database included the unique personal identification number, registered in the Danish Civil Registration System (CRS) ${ }^{20}$ This enabled us to identify every person included in our study, and to merge the study database with national register data on hospitalisation, morbidity, mortality and use of municipal health services. ${ }^{21-23}$ 
Table 3 Mortality, frail versus non-frail

\begin{tabular}{clccc}
\hline Death, $\mathbf{n}(\%)$ & $\begin{array}{l}\text { PRISMA } \geq \mathbf{3} \\
\mathbf{n = 6 2 2}(\%)\end{array}$ & $\begin{array}{l}\text { PRISMA }<3 \\
\mathbf{n = 3 5 1} \text { (\%) }\end{array}$ & P value & Adjusted OR (95\% CI) \\
\hline 30 days after discharge & $19(3.1)$ & $9(2.6)$ & 0.69 & $1.18(0.53$ to 2.64$)$ \\
\hline 0 days after discharge & $45(7.2)$ & $16(4.6)$ & 0.11 & $1.63(0.90$ to 2.92$)$ \\
180 days after discharge & $70(11.3)$ & $19(5.4)$ & 0.003 & $2.20(1.30$ to 3.72$)$ \\
\hline 60 days after discharge & $92(14.8)$ & $23(6.6)$ & $<0.001$ & $2.46(1.53$ to 3.97$)$ \\
\hline
\end{tabular}

Adjusted for age, gender and municipality.

PRISMA, Program of Research to Integrate Services for the Maintenance of Autonomy.

Frail individuals in the clinical quality study were offered an intervention with special follow-up in the municipalities after discharge and since this intervention might influence the findings concerning future use of healthcare services, we used data from the time prior to inclusion.

Number of hospital contacts and contacts with the general practitioner (GP) were defined as contacts within 30,90 and 180 days prior to registration in the study database. Use of home help in the municipality was defined as services within 90 days prior to registration in the study database. Mortality was assessed up to 400 days after registration in the study database.

\section{National registers}

Every person residing in Denmark is uniquely registered in the Danish CRS, comprising a social security number which can be used for linking administrative and health information. ${ }^{24}$ We examined use of hospital services by merging the study database with the Danish National Patient Register, which records all hospital contacts in Denmark. ${ }^{20}$ In addition, the study database was linkedusing the social security number-with information on death/immigration from the database for social integration and information on use of home care and other municipal services from Statistics Denmark. ${ }^{25}$

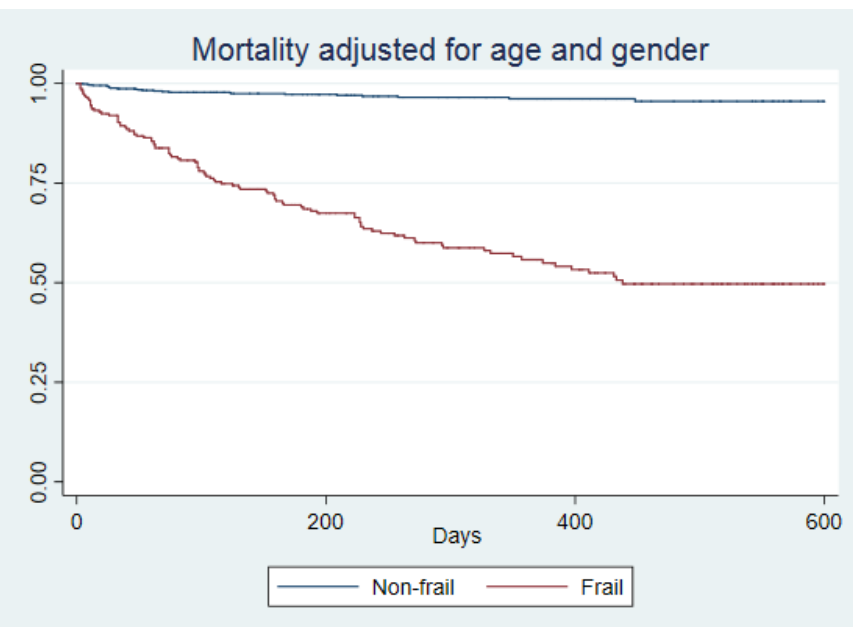

Figure 1 Kaplan-Meier plot showing differences in mortality. The figure shows mortality in frail and non-frail individuals. Mean time at risk was 262.3 days, median 238 days.

\section{Translation of PRISMA-7}

To ensure content and meaning, a Danish physician proficient in English translated the questionnaire into Danish. A Danish scientist, who lived and worked for more than 30 years in the UK, then back translated the questionnaire into English. We found no differences in meaning between the two versions.

\section{Statistical analysis}

We applied a dichotomous frailty measure with PRISMA score $\geq 3$ indicating frailty. We investigated the association between frailty and use of healthcare services in linear and logistic regression models. The PRISMA score captures the effect of age and gender; hence, the regression models were only adjusted for area of residence. The hospital catchment area comprises three local authorities: Lolland, Guldborgsund and Vordingborg, with Lolland being the most destitute of the three. Patients living outside the catchment area were grouped into the Vordingborg area. Vordingborg was baseline and thus the regression output reflected differences between the three local authorities. We regarded these estimates of being of purely local political interest and they are therefore not reported in the tables.

In the descriptive statistics, statistical significance was tested by $\chi^{2}$ tests for difference in proportions and t-test for mean differences between frail (PRISMA $\geq 3$ ) and non-frail (PRISMA <3).

Finally, mortality was assessed in a Kaplan-Meier survival analysis, adjusting for age and gender. In addition, we tested differences in survival at three points in time: 1,3 and 6 months after the index admission in a set of logistic regressions, adjusting for municipality only.

\section{Patient and public involvement}

The clinical quality study was part of a national strategy of optimising the information delivery process and cooperation between hospitals and municipalities when frail elderly patients are discharged from hospital. A local steering group with representatives from regional health authorities and a representative from the local hospital patient committee assisted in planning of the study. 


\section{RESULTS}

Baseline characteristics of the 973 included patients are shown in table 1 . Patients were discharged mainly from orthopaedic surgery departments (53\%) and from medical departments (34\%). A minor proportion of patients were discharged from the emergency room (9\%) and from other departments (4\%). Mean age of frail individuals was 84.8 years (SD 5.74) and of non-frail 80.4 years (SD 3.72), $\mathrm{p}<0.001$. More men than women were frail, $\mathrm{p}<0.001$. Of the seven PRISMA questions, all but one scored higher in the frail group than in the non-frail group. In item 6, participants answer the question, 'If you need help, can you count on someone close to you?' A YES counts for frailty and a NO for non-frailty. In item 6, we found no significant difference in scores among frail individuals compared with non-frail.

Frail individuals used significantly more GP services, more hospital admissions and more days spent in hospital, see table 2.

Table 2 shows the mean number of hospital admissions, the mean number of days spent in hospital and the mean number of contacts to the GP, during 30, 90 and 180 days prior to the index admission.

Mortality rates 180 and 360 days after the index hospitalisation were significantly higher among the frail compared with non-frail, as shown in table 3 and in figure 1.

Frail patients use a significantly higher amount of home care, see table 4.

\section{DISCUSSION}

In this study, we applied PRISMA-7 to a highly selected in-hospital population. We found a very high proportion $(63.9 \%)$ of frail patients among the participants. Frailty was associated with higher utilisation of health services in hospitals and in municipalities; and frailty was associated with a higher mortality 180 and 360 days after discharge. Since selection of participants was based on need of further physical training in hospitalised individuals aged $75+$ years, the large proportion of frailty among participants is not surprising. The prevalence and impact of frailty has been studied in many previous studies, mostly among communitydwelling individuals. In their landmark study including community-dwelling individuals aged 65+, Fried et al found a prevalence of $6.9 \% .{ }^{26}$ In a European study covering the countries Austria, Denmark, France, Germany, Greece, Italy, the Netherlands, Spain, Sweden and Switzerland, the prevalence among community-dwelling individuals 65 years and above the mean prevalence was $17.0 \%$ (range 5.8-27.3). ${ }^{27}$

Fewer studies have examined prevalence and adverse outcomes of frailty among hospitalised patients. However, Cunha et al recently summarised the findings in a metaanalysis and reported a 6-month mortality of 13.2\%-23\% among the frail compared with $0 \%-7.1 \%$ among the non-frail. ${ }^{28}$

In a meta-analysis, Vermeiren $e t a t^{29}$ summarised the impact of frailty and found a negative impact on several health outcomes including hospitalisation and mortality with an OR for premature mortality of 2.34 (1.77-3.09), which is close to our finding of OR 2.46 for 1-year mortality among frail compared with non-frail individuals.

In a longitudinal observational study, Gilardi et al found frail community-dwelling adults above the age of 65 to have increased 1-year mortality with $10.1 \%$ among the frail and $19.1 \%$ among the very frail compared with $4.2 \%$ among the robust. These findings are comparable to our findings as shown in table $3 .^{30}$ 
In contrast to the original PRISMA-7 development study, ${ }^{7}$ in our study item 6 did not contribute to the distinction between frail and non-frail. Item 6: 'If you need help, can you count on someone close to you?' renders the following response options: a YES counts for frailty and a NO for non-frailty. In our population, only $9 \%$ of the participants answered NO to item 6 , and these participants were equally distributed among the two groups. In the original development of PRISMA-7, the questionnaire was distributed to communitydwelling elderly people in Canada. Our different findings concerning item 6 are probably mainly due to differences in design and setting. Among communitydwelling adults, the fact that elderly individuals have thought of the question whether they would have anyone to help them if necessary may arise from feeling the need of help. Among hospitalised elderly individuals, the proportion of elderly individuals needing help is probably large and it is natural for most individuals to have thought about the question. Another possible explanation for our finding may be the very easy access to help from the municipality in Denmark. Based on our findings, item 6 in PRISMA-7 might be removed from the questionnaire when used in an in-hospital setting; however, this needs further assessment.

\section{Strengths and weaknesses}

PRISMA-7 has to our knowledge never been evaluated in Denmark and has only in very few studies been evaluated in an in-hospital setting. ${ }^{12} 13$ Our main finding, that PRISMA-7 even in a selected hospital population can identify a group of patients with a higher need of hospital treatment and care in the community, renders it plausible that PRISMA-7 can be used to identify in-hospital patients that may benefit from further geriatric assessment.

We have shown that PRISMA-7 in this setting has predictive validity comparable to other frailty measures. However, we have not examined other aspects of validity such as construct validity or face validity.

\section{CONCLUSION}

This study provides evidence that PRISMA-7 can identify frail elderly patients in an in-hospital setting and in a selected patient population. The findings indicate that PRISMA-7 may have a future role in identifying patients who can benefit from further geriatric assessment. However, there is a need for further studies in order to conclude on test accuracy in a broader in-hospital setting.

Contributors SH contributed in designing the study and made the first draft of the article. AW and MK performed the statistical analysis. KKJ and MAL contributed in interpretation of data analysis. EAH contributed in the design of the study, interpretation of data analysis and revision of the first draft. All authors performed critical revision of the article draft and approved the final version. All authors agree to be accountable for all aspects of the work.

Funding The study received funding from the National Ministry of Health.
Disclaimer The funding source had no influence on study design, data analysis or interpretation.

Competing interests None declared.

Patient consent for publication Not required.

Ethics approval The study database was approved by the Danish Data Protection Agency, REG-070-2017. In Denmark, register-based studies do not require approval by an ethical committee.

Provenance and peer review Not commissioned; externally peer reviewed.

Data availability statement No data are available. The data used for the analyses cannot be made available publicly, as they fall under the definition of sensitive personal data in the European General Data Protection Regulation. Metadata will be made available upon publication.

Supplemental material This content has been supplied by the author(s). It has not been vetted by BMJ Publishing Group Limited (BMJ) and may not have been peer-reviewed. Any opinions or recommendations discussed are solely those of the author(s) and are not endorsed by BMJ. BMJ disclaims all liability and responsibility arising from any reliance placed on the content. Where the content includes any translated material, BMJ does not warrant the accuracy and reliability of the translations (including but not limited to local regulations, clinical guidelines, terminology, drug names and drug dosages), and is not responsible for any error and/or omissions arising from translation and adaptation or otherwise.

Open access This is an open access article distributed in accordance with the Creative Commons Attribution Non Commercial (CC BY-NC 4.0) license, which permits others to distribute, remix, adapt, build upon this work non-commercially, and license their derivative works on different terms, provided the original work is properly cited, appropriate credit is given, any changes made indicated, and the use is non-commercial. See: http://creativecommons.org/licenses/by-nc/4.0/.

ORCID iDs

Marie Kruse http://orcid.org/0000-0001-7159-8781

Ellen Astrid Holm http://orcid.org/0000-0002-7600-6025

\section{REFERENCES}

1 Rodríguez-Mañas L, Féart C, Mann G, et al. Searching for an operational definition of frailty: a Delphi method based consensus statement: the frailty operative definition-consensus conference project. J Gerontol A Biol Sci Med Sci 2013;68:62-7.

2 Clegg A, Young J, lliffe S, et al. Frailty in elderly people. Lancet 2013;381:752-62.

3 Campbell AJ, Buchner DM. Unstable disability and the fluctuations of frailty. Age Ageing 1997;26:315-8.

4 Pilotto A, Cella A, Pilotto A, et al. Three decades of comprehensive geriatric assessment: evidence coming from different healthcare settings and specific clinical conditions. J Am Med Dir Assoc 2017;18:192.e1-11.

5 BGS. Fit for frailty, consensus best practice guideline for the care of older people living with frailty in the community and outpatient settings. Available: http://www.bgs.org.uk/campaigns/fff/fff_full.pdf [Accessed 18 Jul 2020].

6 Clegg A, Rogers L, Young J. Diagnostic test accuracy of simple instruments for identifying frailty in community-dwelling older people: a systematic review. Age Ageing 2015;44:148-52.

7 Hébert R, Durand PJ, Dubuc N, et al. PRISMA: a new model of integrated service delivery for the frail older people in Canada. Int $J$ Integr Care 2003;3:e08.

8 Hébert R, Durand PJ, Dubuc N, et al. PRISMA: a new model of integrated service delivery for the frail older people in Canada. Int $J$ Integr Care 2003;3:992-7.

9 Turner G, Clegg A, et al, British Geriatrics Society. Best practice guidelines for the management of frailty: a British geriatrics Society, age UK and Royal College of general practitioners report. Age Ageing 2014;43:744-7.

10 BGS. Fit for frailty. Available: https://www.bgs.org.uk/sites/default/ files/content/resources/files/2018-05-14/fff2_short_0.pdf [Accessed 18 Jul 2020].

11 O'Caoimh R, Costello M, Small C, et al. Comparison of frailty screening instruments in the emergency department. Int J Environ Res Public Health 2019;16. doi:10.3390/ijerph16193626. [Epub ahead of print: 2709 2019].

12 Beauchet O, Fung S, Launay CP, et al. Screening for older inpatients at risk for long length of stay: which clinical tool to use? BMC Geriatr 2019;19:156. 
13 Elliott A, Phelps K, Regen E, et al. Identifying frailty in the emergency Department-feasibility study. Age Ageing 2017;46:840-5.

14 Saenger ALF, Caldas CP, Raîche M, et al. Identifying the loss of functional independence of older people residing in the community: validation of the PRISMA-7 instrument in Brazil. Arch Gerontol Geriatr 2018;74:62-7.

15 Abbasi M, Khera S, Dabravolskaj J, et al. Identification of frailty in primary care: feasibility and acceptability of recommended case finding tools within a primary care integrated seniors' program. Gerontol Geriatr Med 2019;5:233372141984815.

16 Salminen M, Viljanen A, Eloranta S, et al. Frailty and mortality: an 18-year follow-up study among Finnish community-dwelling older people. Aging Clin Exp Res 2020;32:2013-9.

17 Yaman $\mathrm{H}$, Ünal $\mathrm{Z}$. The validation of the PRISMA-7 questionnaire in community-dwelling elderly people living in Antalya, Turkey. Electron Physician 2018;10:7266-72.

18 Braun T, Grüneberg C, Thiel C. German translation, cross-cultura adaptation and diagnostic test accuracy of three frailty screening tools : PRISMA-7, FRAIL scale and Groningen Frailty Indicator. Z Gerontol Geriatr 2018;51:282-92.

19 Saenger ALF, Caldas CP, Motta LB. [Cross-cultural adaptation of the PRISMA-7 instrument for use in Brazil: evaluation of conceptual, item, and semantic equivalences]. Cad Saude Publica 2016;32:e00072015.

20 Lynge E, Sandegaard JL, Rebolj M. The Danish national patient register. Scand J Public Health 2011;39:30-3.
21 Andersen JS, Olivarius NDF, Krasnik A. The Danish National health service register. Scand J Public Health 2011;39:34-7.

22 Helweg-Larsen K. The Danish register of causes of death. Scand J Public Health 2011;39:26-9.

23 Vest-Hansen B, Riis AH, Christiansen CF. Registration of acute medical hospital admissions in the Danish national patient registry: a validation study. Clin Epidemiol 2013:5:129-33.

24 Schmidt M, Pedersen L, Sørensen HT. The Danish civil registration system as a tool in epidemiology. Eur J Epidemiol 2014;29:541-9.

25 Dream. Available: https://www.dst.dk/-/media/Kontorer/13Forskning-og-Metode/DREAM-koder-version-44-E.pdf?la=da [Accessed $18 \mathrm{Jul} 2020]$.

26 Fried LP, Tangen CM, Walston J, et al. Frailty in older adults: evidence for a phenotype. J Gerontol A Biol Sci Med Sci 2001:56:M146-57.

27 Santos-Eggimann B, Cuénoud P, Spagnoli J, et al. Prevalence of frailty in middle-aged and older community-dwelling Europeans living in 10 countries. J Gerontol A Biol Sci Med Sci 2009;64:675-81.

28 Cunha AIL, Veronese N, de Melo Borges S, et al. Frailty as a predictor of adverse outcomes in hospitalized older adults: a systematic review and meta-analysis. Ageing Res Rev 2019;56:100960.

29 Vermeiren S, Vella-Azzopardi R, Beckwée D, et al. Frailty and the prediction of negative health outcomes: a meta-analysis. J Am Med Dir Assoc 2016;17:1163.e1-1163.e17.

30 Gilardi F, Scarcella P, Proietti MG, et al. Frailty as a predictor of mortality and hospital services use in older adults: a cluster analysis in a cohort study. Eur J Public Health 2018;28:842-6. 